\title{
Diesel Engine Injector Faults Detection Using Acoustic Emissions Technique
}

\author{
F.Elamin, F.Gu, A. Ball \\ School of Computing and Engineering, University of Huddersfield \\ Queensgate, Huddersfield, HD1 3DH, UK \\ E-mail: f.elamin@hud.ac.uk
}

\begin{abstract}
This study focuses on investigation of the method of identifying injector faults in a JCB 444T2 diesel engine using acoustic emission (AE) technique. Different kinds of injector faults were seeded in the four-cylinder, four-stroke, and turbo-engine. Then, faulty injectors are tested to evaluate AE based injection fault detection. The AE signals recorded from the tests were processed in the angular, frequency and joint angular-frequency domain. The results from joint angular-frequency analysis have shown that $\mathrm{AE}$ can clearly monitor the changes in the combustion process due to its high signal to noise ratio, where other vibro-acoustic sources have little influence. Using features in the AE signal, faults of injector can be identified during the operation of the engine.
\end{abstract}

Keywords: Diesel engine, Injector faults, Fault detection, Acoustic emission

\section{Introduction}

Today's diesel engines must meet both fuel economy requirements and pollutant emissions regulations. These regulations become ever more and more stringent moving from euro V to Euro VI and into the future. Faults in fuel injectors cause, not only low engine efficiency but also high and sometimes even unacceptable level of unburned hydrocarbons caused by poor air fuel ratios. In addition, injector faults increases noise and vibration which may cause damage to engine components. Therefore, the detection injector faults at their early stage and maintain combustion performance is one of key tasks in controlling pollutant emission as an engine ages and not just its early life performance.

Many previous researchers have been carried out for engine fuel injection diagnosis (F. Gu and A. D. Ball, 1996)(F. Gu and A. D. Ball, 1996)(Rezeka, S. F. and Henein, N. A. 1987) based on airborne acoustics and structural borne vibration. However, because of complexity of vibro-acoustic sources in a diesel engine, it is difficult to obtain detailed information regarding to fuel injection for reliable fault diagnosis. In contrast, acoustic emission (AE) from engines usually may be a more effective approach to detecting injection related faults because it is measured in high frequencies such as $100 \mathrm{kHz}$ above and hence has the good localisation performance.

AE measurement on the cylinder head is a non-intrusive method and has been successfully implemented for monitoring diesel engines (J. Antoni, J. Danière, F. 2002)(J. Antoni, J. Danière, F. Guillet, 2004)(L. Stankovic, J. F. Böhme, 1999). Various signal processing techniques of the AE signals are used to extract features sensitive to faults. These investigations have shown that the AE signals have a very high signal-to-noise ratio and the faults of interest can be extracted with certain effort in signal processing.

The AE signals measured on the diesel engine depend on the excitations and the propagation path. The main sources of excitation are likely to affect the engine AE response, include impacts due to piston clearances (piston slaps), fuel injection high rise of gas pressure during combustion and the impacts of inlet and exhaust valves. Some of these faults affect the AE signal simultaneously and during a limited portion of the engine cycle.

A fault is usually detected by comparing the AE signal of the faulty engine to the reference signature. In the angular domain the presence of several simultaneous faults makes the separation of the sources a difficult task. Fourier spectrum is more useful for the analysis of stationary signals associated to reciprocating machines. For non-stationary engine AE signals, the spectrum tends to smear frequency components. Joint angular-frequency analysis has more potential for source separation since both the frequency content and time varying profile of the signal can be investigated simultaneously.

In this paper, the potential for early detection of injector faults using AE signals is investigated experimentally. For the experimental work a four-stroke, four-cylinder, turbocharged, in-line diesel engine has been used. AE signals have been recorded under different healthy conditions and analysed correspond in the angular, frequency and joint angular-frequency domains to extract key characteristics from the raw AE signals for differentiate different engine conditions. 


\section{AE Sources in Diesel Engines}

There many possible AE sources in diesel engines. Previous studies (M.H. El-Ghamry, R.L. Reuben and J.A. Steel, 2003)(P. Nivesrangsan, J.A. Steel, R.L. Reuben, 2005)(P. Nivesrangsan, J.A. Steel, R.L. Reuben, 2007)(F.Elamin, Y. Fan, F. Gu and A. Ball, 2009) have shown that AE measured at cylinder head contains major $\mathrm{AE}$ events from combustion, fuel injection piston slaps and valve impacts. In the following, possible AE sources of a diesel engine, as well as the mechanism of propagation of these sources to the engine structure are reviewed for best understanding of $\mathrm{AE}$ signals measured from different engines at different locations.

\subsection{Combustion}

During the phase of combustion a significant and rapid increase of the in-cylinder pressure occurs to force piston moving down. The high pressure rise rate during combustion, creates a force that can be described as comparable to a hammer hit and hence can cause wideband responses on the cylinder and cylinder head. At higher engine conditions the higher impacts will be resulted by higher pressure increases. Previous studies confirmed that this excitation is periodic according engine working cycle and spreads to wide frequencies as high as several kilo-Hertz.

As the impact of the combustion pressure applies a direct excitation on the cylinder head. This path constitutes the first way of propagation and can be observed easily by placing AE sensor on proper place on the cylinder head

\subsection{Piston Slap}

Piston slap is another important source of acoustic emission in diesel engines. It is caused by the inversion of the inertia forces acting on the piston as the piston changes direction at top dead centre TDC and bottom dead centre BDC. This effect is most prominent when the force from the combustion process is acting on the piston. Piston slap results from the succession of two strong impacts. One impact is applied by the upper part of the piston near the crown while the other impact is applied by the lower part of the piston skirt. The upper impact is usually higher than the lower due to high gas force in combustion cycle. The piston slap impacts also cover a wide range of frequencies and vary significantly with engine operating conditions. The dimensions of clearance between piston and cylinder are the most decisive factor of the impact intensity and hence these types of AE events may not be observed directly when the clearance is small. Nevertheless piston slap is very close to TDC and may be masked by combustion event.

\subsection{Fuel Injection}

The fuel injection process in a diesel fuel is driven by a high pressure (several hundred bars) in short time duration (several micro-seconds). It causes both mechanical impacts and flow friction. During fuel injection the high pressure fuel wave makes the needle valve opening and closing, which produces the mechanical impacts due to the valve motion and hence possible AE events. In the mean time, a high speed flow formed in the orifices of injector may also produce $\mathrm{AE}$ signals due to complicated hydrodynamic processes such as fuel atomization, interaction between the flow jet and orifices. This fuel injection related AE's occur before TDC and have much smaller amplitude compared with combustion induced AE.

\subsection{Valve Impact}

Closing and opening of intake and exhaust valves is achieved by a camshaft and a valve spring operating in precise synchronisation. AE events from the valves in a diesel engine arise from two sources of distinctly different origin and character, namely:

1) Mechanical impact is generated by the colliding of various surfaces, in particular those of the valve and valve seat, and of the rocker arm with push rod or valve stem. Valve impact is considered to be the predominant source of $\mathrm{AE}$ events from the valve.

2) Aerodynamic friction is created by the high speed gas passing between the valves and their seating, and gas flow over the valve face.

Valve impact plays a significant role in the AE of diesel engines and these impacts on the valve seat on valve closure, and the degree of impact depends on the valve closing velocity, which is controlled by the dynamic behaviour of the valve train, particularly the force exerted on the valve by the valve spring.

\section{AE Measurements}

AE signals studied in this paper are from an in-line four-cylinder diesel engine, whose combustion sequence for each cylinder is 1-3-4-2. Full operating parameters and characteristics of the engine are given in Table 1. 
A wide band frequency AE sensor was placed on the front side of cylinder head so that AE characteristics from Cylinder 1 can be studied with great details, as shown in Figure 1. The output or AE sensor is amplified and sampled at $2 \mathrm{MHz}$ for more accurate waveform analysis. Raw AE signals were collected under constant engine speed: $1000 \mathrm{rpm}$ and 4 different load conditions: $0,50 \mathrm{Nm}, 100 \mathrm{Nm}$ and $150 \mathrm{Nm}$.

For a study of AE signal based engine injector fault diagnosis, four tests were conducted under different engine conditions. Test 1 is for the baseline AE data collected when the engine is healthy. Test 2 is for a small fault in cylinder 1 under an abnormal fuel injection pressure induced by setting it $15 \%$ lower than the nominal injection pressure of $270 \mathrm{bar}$.

Test 3 is for a small fault in cylinder 1 under an abnormal fuel injection pressure induced by setting it $20 \%$ higher than the nominal injection pressure. Test 4 is for a large fault induced by disconnecting fuel supply to cylinder 1 to simulate a full misfired engine as seen in Figure 2.

\section{Signal Analysis and Result}

\subsection{Analysis in the Angular Domain}

Based on the raw AE signals measured, the engine speed is estimated and corresponding crank angles are calculated based constant speed operation. Figure 3 presents the AE signals aligned in the angular domain under different loads at 1000rpm. In addition, the events relating to inlet valve opening (IVO), inlet closing (IVC), exhaust valve opening (EVO) and exhaust valve closing (EVC) are also illustrated based on their corresponding nominal values. It can be seen that there are four major AE events can be observed clearly in one full engine cycle for this four cylinder engine. This alignment is just based on the amplitude trend with engine load without the measurement of TDC signals. In particular, the amplitude change in is more consistent with the increasing in engine load and hence with AE generation mechanisms, i.e. a higher load generating a high combustion AE event. In contrast, other AE components maintain nearly constant with load, showing that they are mainly come from valve events. Besides a small $\mathrm{AE}$ event showing around $190^{\circ}$ is also consistent with the closure of inlet valve 1.

However, the largest event is aligned with the event due to the opening of inlet valve in cylinder 1 and its amplitude is similar over different load conditions. This observation is different from previous study that the combustion is the largest AE event (M.H. El-Ghamry, R.L. Reuben and J.A. Steel, 2003)(P. Nivesrangsan, J.A. Steel, R.L. Reuben, 2005)(P. Nivesrangsan, J.A. Steel, R.L. Reuben, 2009), which demonstrates that AE characteristics are very different between different engine designs.

Figures 4, 5 and 6 show the comparison of healthy AE signals with that from the three seeded faults respectively. For the reduced injection pressure fault, a clear difference just before $360^{\circ}$, shown in Figure 4(a), can be seen under no load operation whereas they are very similar for other load conditions. Even though, the rapid transient event of the no load condition indicates that an obvious injector valve impact due to the pressure reduction, however, for other load conditions this feature is not so clearly observed in this angular domain presentation. This shows that more advanced analysis is required to achieve full injector fault diagnosis.

For the increased injection pressure fault, a clear difference just around $360^{\circ}$, shown in Figure 5 (a), can be seen under no load operation whereas they are nearly similar for other load conditions.

For the full misfired cylinder, AE signal in Figure 6 show no clear AE event for all load condition tests and hence allows the misfire to be detected straightforward in the angular domain.

\subsection{Analysis in the Frequency Domain}

The AE signals in the frequency domain are obtained by applying the Fast Fourier Transformation (FFT) to raw AE signals. Figures 7, 8 and 9 give spectral comparison for three faulty cases respectively. It can be seen that high AE energy is mainly in a frequency range from $10 \mathrm{kHz}$ to $45 \mathrm{kHz}$ and there is clear change can be observed in the spectrum between the healthy and faulty cases. For both three faulty cases, the main frequency components shift slightly to higher frequency bands. It may indicate that engine behaves with sharper impacts or more violent flow processes, which are basic symptoms of the faulty operation.

However, it is impossible to determine which cylinder has a faulty injector from the spectrum and to differentiate between the three faulty cases.

\subsection{Analysis in the Angle-Frequency Domain}

The analysis discussed in the previous show that AE signals in the angular domain can produce diagnosis results for no load condition but not for higher load conditions whereas spectrum presentation allows fault deletion for all cases but not diagnosis. To combine the capabilities in both the angular and frequency domains, joint 
angular-frequency analysis is applied to the AE signals. Previously work in (F. Gu and A. D. Ball, 1996)(F. Gu and A. D. Ball, 1996) shows that smoothed Wigner distribution is effective in analysis injector impact induced vibration. However, recent advances in signal processing show that wavelet transforms is more suitable in analysis highly non-stationary signals such as AE from engines. Therefore, the measured AE signals is analysed with a continuous wavelet transform (CWT) using a Morlet wavelet. For more detailed study, CWT results are presented around the combustion TDC of cylinder 1.

The top two graphs in Figure 10 show CWT results of healthy engine under no load and a high load respectively. It can be seen that combustion $\mathrm{AE}$ events occurs around $365^{\circ}$ and its frequency content become higher under high load condition. In addition, its amplitudes also increase. The AE event due to fuel injection happen around $355^{\circ}$ and both its frequency range and amplitude increase with load.

For the small fault of the lower injection pressure (85\%), CWT results change significantly from that of healthy case. CWT results shown by bottom graphs have higher AE amplitudes, indicating higher impact from needle valve opening due to reduced injection pressure. For the no load case, it shows little combustion AE event whereas around $365^{\circ}$, indicating poor combustion occurring in the cylinder. In contrast, the high load condition show a very high $\mathrm{AE}$ combustion event with wider frequency range. This shows that the combustion occurs violently because of poor fuel atomization and more fuel injected caused by reduced injection pressure.

Figure 11 shows the small fault of the higher injection pressure (120\%), CWT results significantly from that healthy case. CWT results shown by bottom graphs have very low AE amplitude at no load and higher amplitude at high load. This is indicating very lower impact from needle valve opening due to increased injection pressure. For the no load case, it shows little combustion $\mathrm{AE}$ event whereas around $365^{\circ}$, indicating very poor combustion occurring in the cylinder. In contrast, the high load condition show an extremely very high AE combustion event with smaller frequency range. This shows that the combustion occurs forcefully because of good fuel atomization and less fuel injected caused by increased injection pressure.

These significant changes due to the fault in CWT shows that it is possible to differentiate the small injection fault from healthy and achieve diagnosis under both high and low load conditions.

Figure 12 present the comparison of CWT results between the healthy case and the full misfire under both low and high load conditions. It is obvious that neither combustion AE event nor injection shows on CWT results and hence this fault can be detected and diagnosed without problems.

\section{Conclusion}

This experimental study has shown that AE signals from a four cylinder diesel engine are shown to be effective for the detection of injector faults.

The analysis in the angular domain provides a straightforward method to identify small malfunctions of the injector only under no load operations. The analysis in the frequency domain can produce fault detection for both faults but cannot identify differences between different sources and types of faults. The joint angular-frequency analysis can provide both detection and diagnosis for both the small and large injection faults and their original cylinder and has the potential of separating several AE sources occurring at the same time but having different frequency content. It was found that the main $\mathrm{AE}$ transients were generated by the inlet valve opening in each cylinder and the faults of injection can be reflected in these main AE transients through their influence on the $\mathrm{AE}$ events.

Further research work will be conducted to extract more features from the angular-frequency results using different methods. The engine faults may then be identified using these features.

\section{References}

F. Gu and A. D. Ball. (1996). Diesel Injector Dynamic Modelling and Estimation of Injection Parameters from Impact Response, Part 1 - Modelling and Analysis of Injector Impacts, Proc. of the I.Mech.E. Part D - Journal of Automobile Engineering, vol.210, pp.293-302, 1996.

F. Gu and A. D. Ball. (1996). Diesel Injector Dynamic Modelling and Estimation of Injection Parameters from Impact Response, Part 2 - Prediction of Injection Parameters from Monitored Vibration, Proc. of the I.Mech.E. Part D - Journal of Automobile Engineering, vol.210, pp.303-312, 1996.

F.Elamin, Y. Fan, F. Gu and A. Ball. (2009). Detection of diesel engine valve clearance by acoustic emission. In: Proceedings of Computing and Engineering Annual Researchers' Conference 2009: CEARC'09. University of Huddersfield, Huddersfield, pp. 7-13. ISBN 9781862180857. 
J. Antoni, J. Danière, F. Guillet. (2004). Cyclostationarity modelling of rotating machine vibration signals, Mechanical systems and signal processing, 18 (2004) 1285-1314.

J. Antoni, J. Danière, F. Guillet. (2002). Effective vibration analysis of IC engines using cyclostationarity. Part I: A methodology for condition monitoring, Journal of Sound and Vibration (2002) 257 (5), 815837.

L. Stankovic, J. F. Böhme. (1999). Time-frequency analysis of multiple resonance in combustion engine signals, Signal Processing (1999) 79 15-28.

M.H. El-Ghamry, R.L. Reuben and J.A. Steel. (2003). The development of automated pattern recognition and statistical feature isolation techniques for the diagnosis of reciprocating machinery faults using acoustic emission, Mechanical Systems and Signal Processing 17 (2003), pp. 805-823.

P. Nivesrangsan, J.A. Steel, R.L. Reuben. (2007). Acoustic emission mapping of diesel engines for spatially located time series-Part II: Spatial reconstitution, Mechanical Systems and Signal Processing 21 (2007), pp1084-1102.

P. Nivesrangsan, J.A. Steel, R.L. Reuben. (2005). AE mapping of engines for spatially located time series, Mechanical Systems and Signal Processing 19 (2005) pp.1034-1054.

Rezeka, S. F. and Henein, N. A. (1987). A diagnostic technique for the identification of misfiring cylinder(s). SAE paper870546, 1987.

Table 1. Description of JCB Engine

\begin{tabular}{|l|l|}
\hline Type of engine & Turbocharged diesel engine \\
\hline Number of cylinders & 4 \\
\hline Bore & $103 \mathrm{~mm}$ \\
\hline Stroke & $132 \mathrm{~mm}$ \\
\hline Compression ratio & 18.3 \\
\hline Number of valves & 16 \\
\hline Injection system & Direct injection \\
\hline Displacement & 4.399 litre \\
\hline Speed range & $850-2200 \mathrm{rpm}$ \\
\hline Recommended speed & $850 \mathrm{rpm}$ \\
\hline Maximum power & $74.2 \mathrm{kw} @ 2200 \mathrm{rpm}$ \\
\hline
\end{tabular}

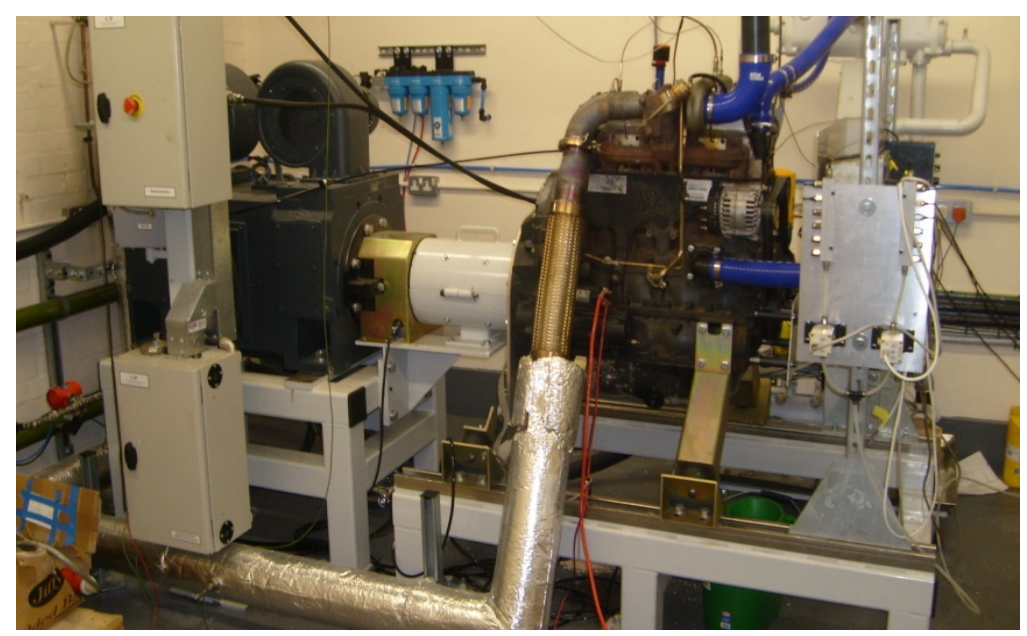

Figure 1. JCB Engine Test Rig 


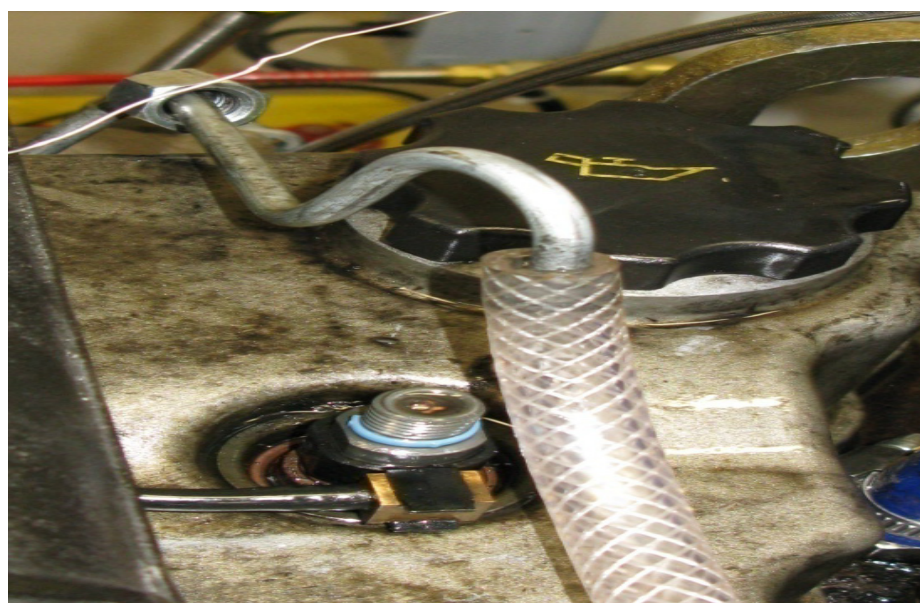

Figure 2. Arrangement for total misfire.

(a) $0 \mathrm{Nm}$ at 998.5 , rpm

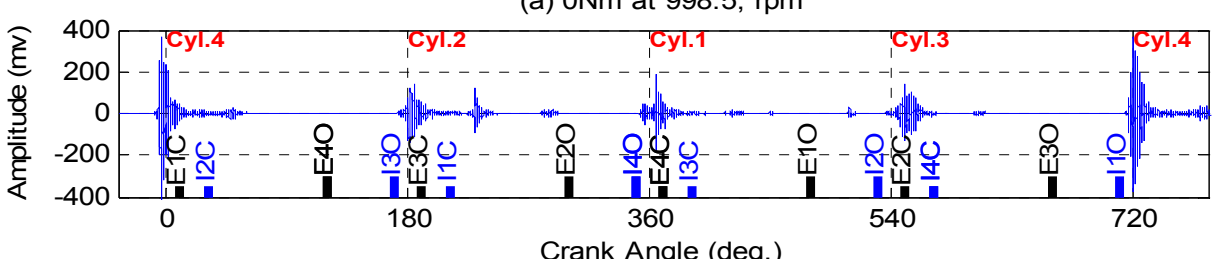

Crank Angle (deg.)

(b) $50 \mathrm{Nm}$ at $975.6, \mathrm{rpm}$

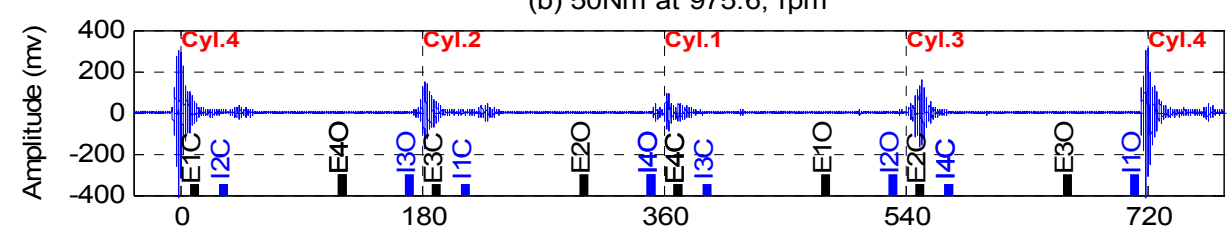

Crank Angle (deg.)

(c) $100 \mathrm{Nm}$ at $998.5, \mathrm{rpm}$

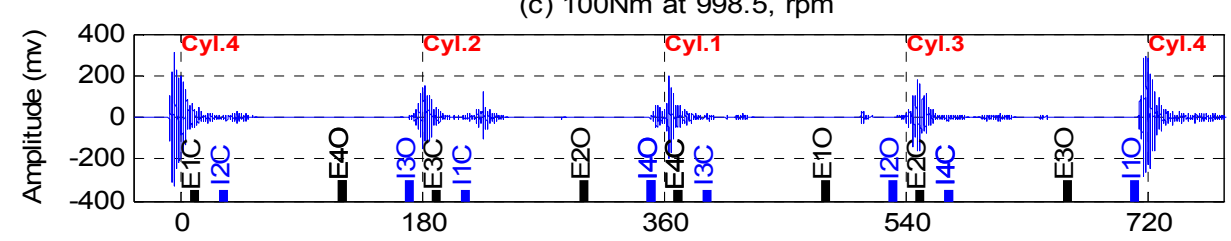

Crank Angle (deg.)

(d) $150 \mathrm{Nm}$ at $1001.4, \mathrm{rpm}$

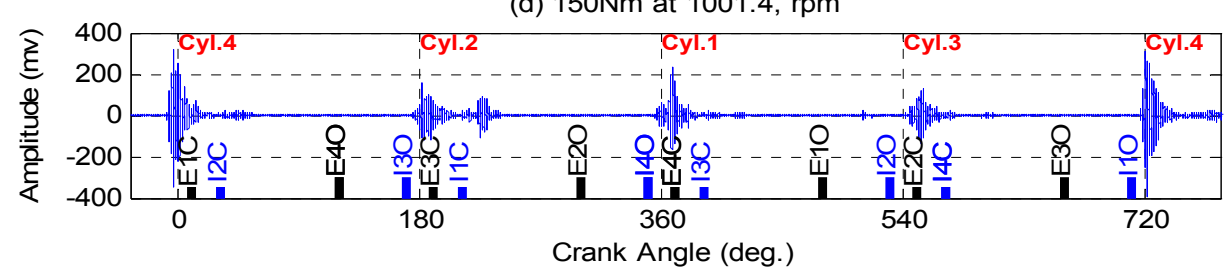

Figure 3. AE signals in the angular domain under different loads 
(a) $\mathrm{ONm}$ at $998.5,949.9 \mathrm{rpm}$

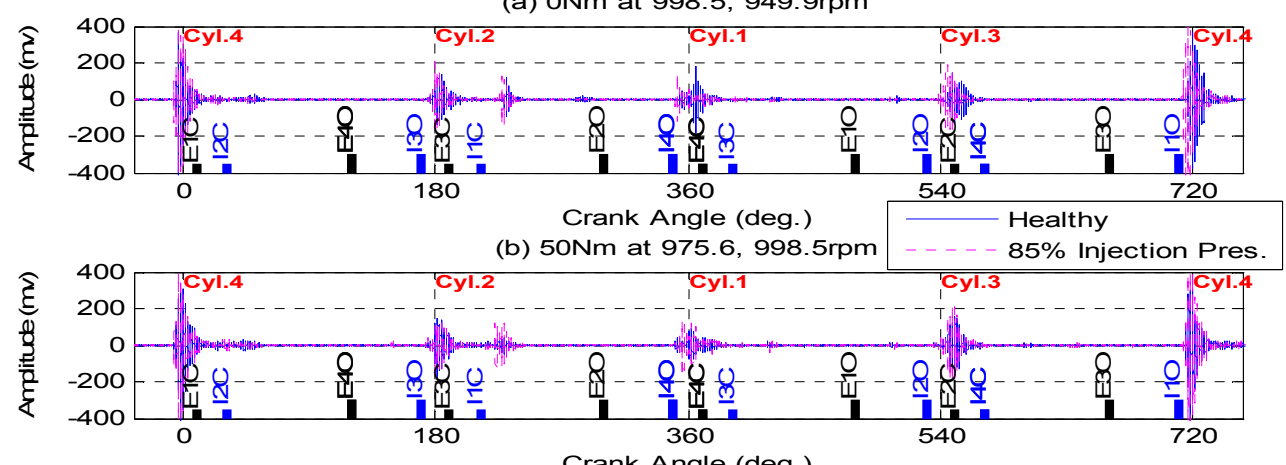

(c) $100 \mathrm{Nm}$ at $998.5,998.5 \mathrm{rpm}$

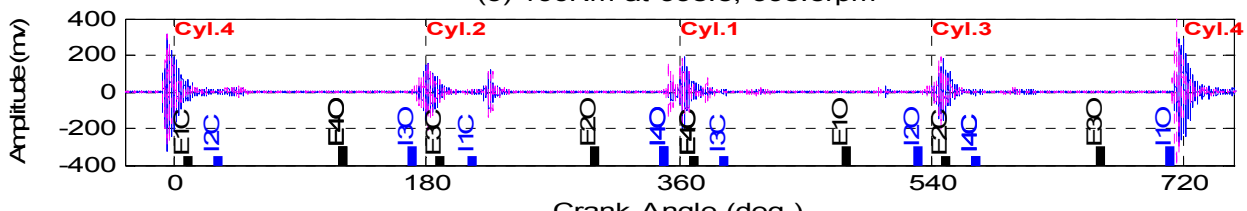

(d) $150 \mathrm{Nm}$ at $1001.4,998.5 \mathrm{rpm}$

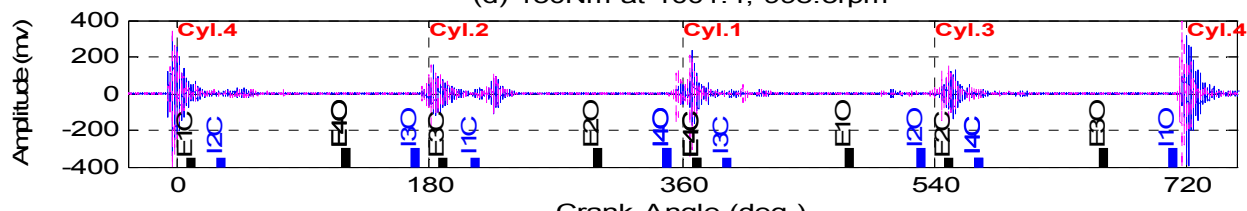

Figure 4. AE signals in the angular domain ( $85 \%$ injection pressure).

(a) $\mathrm{ONm}$ at $998.5,935.6 \mathrm{rpm}$

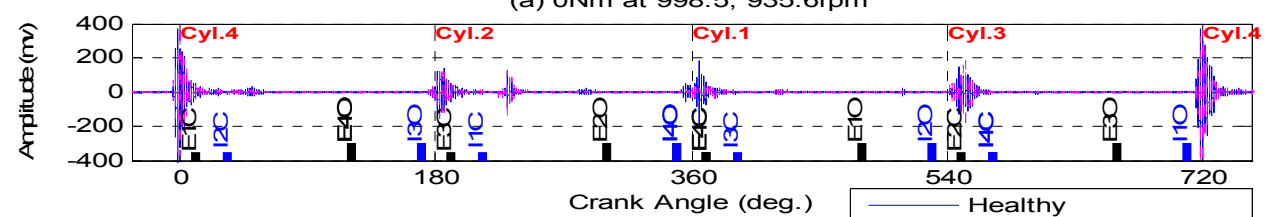

(b) $50 \mathrm{Nm}$ at $975.6,998.5 \mathrm{rp} \ldots \ldots-120 \%$ Injection Pres.

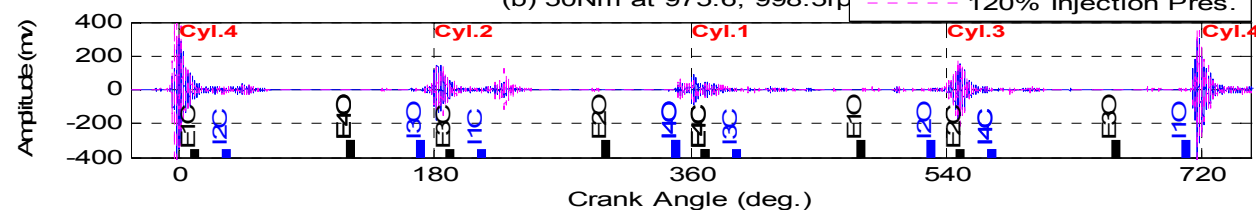

(c) $100 \mathrm{Nm}$ at $998.5,998.5 \mathrm{rpm}$

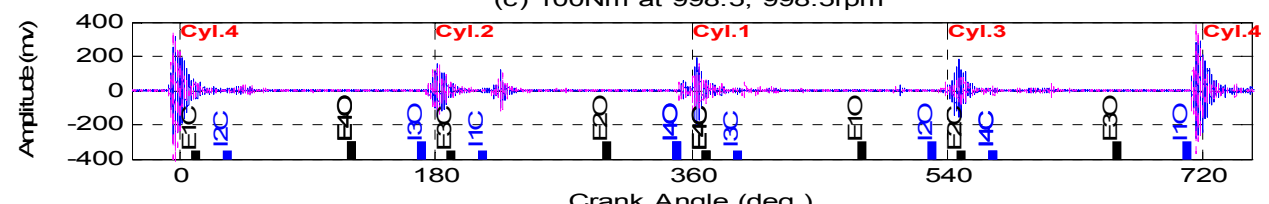

(d) $150 \mathrm{Nm}$ at $1001.4,998.5 \mathrm{rpm}$

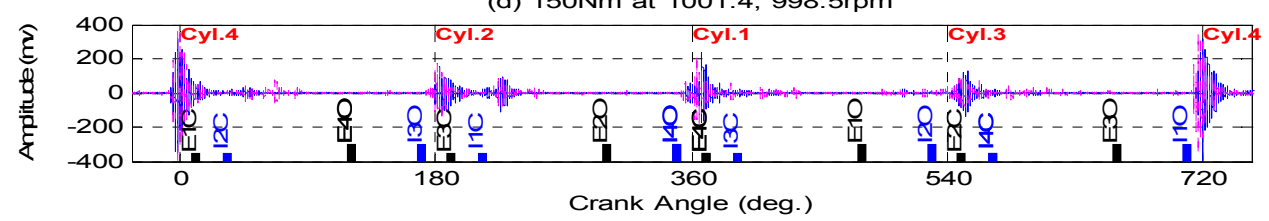

Figure 5. AE signals in the angular domain (120\% injection pressure). 
(a) $\mathrm{ONm}$ at $998.5,955.6 \mathrm{rpm}$

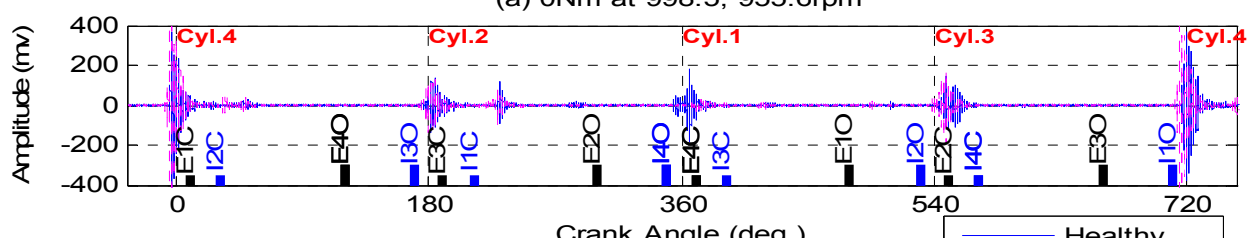

Crank Angle (deg.)

(b) $50 \mathrm{Nm}$ at $975.6,995.6 \mathrm{rpm}$

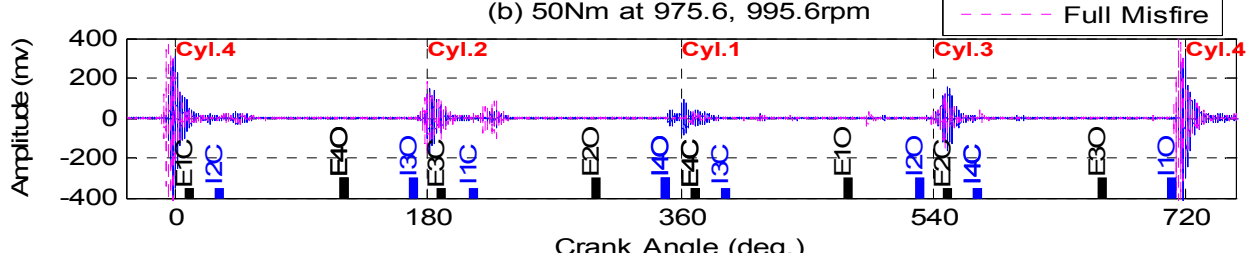

(c) $100 \mathrm{Nm}$ at $998.5,995.6 \mathrm{rpm}$

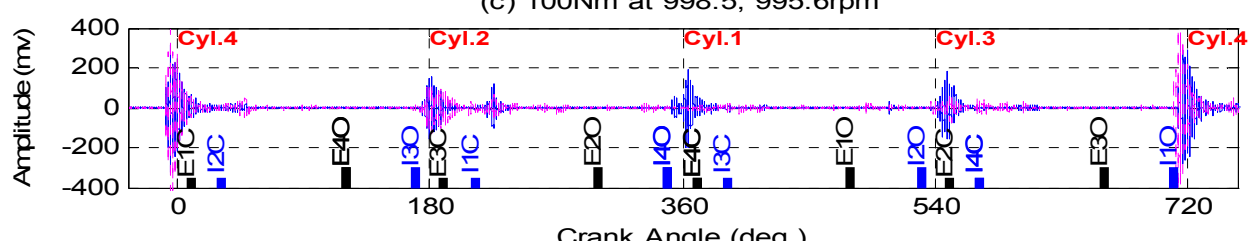

(d) $150 \mathrm{Nm}$ at $1001.4,998.5 \mathrm{rpm}$

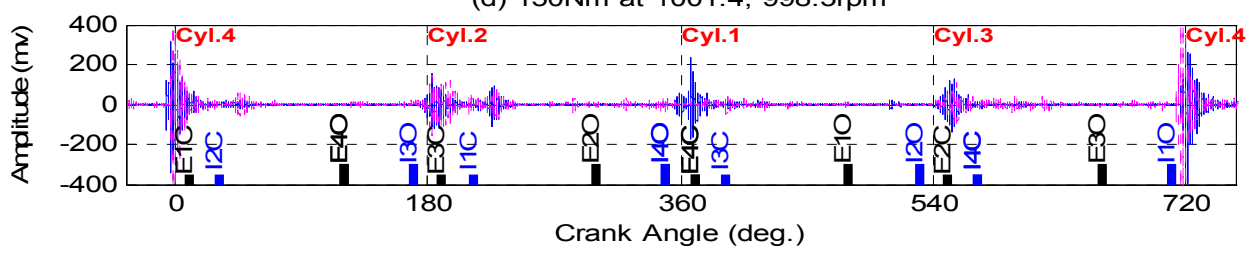

Figure 6. AE signals in the angular domain (full misfire).

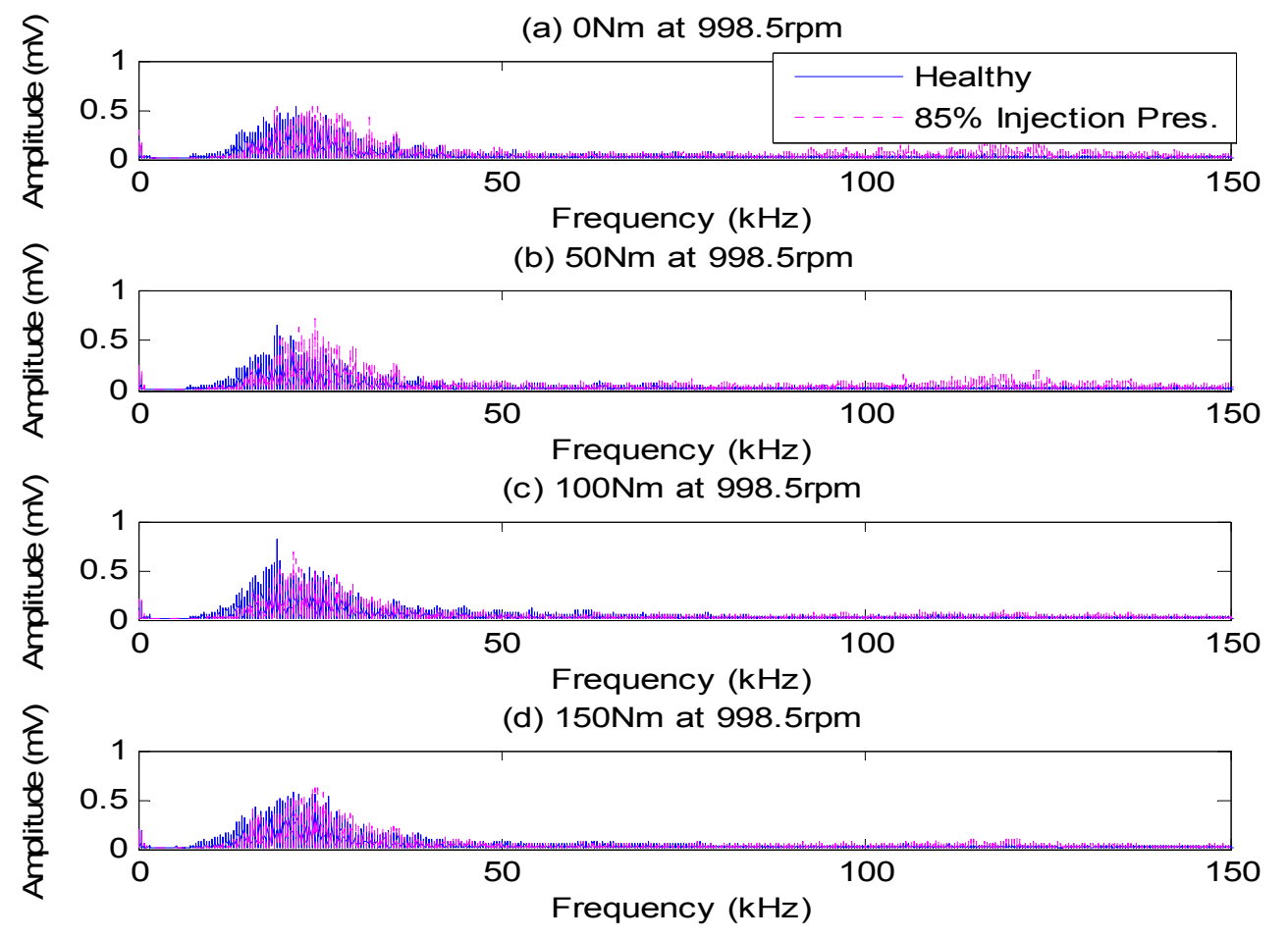

Figure 7. Spectra of the AE signals for $85 \%$ injection pressure 
(a) $0 \mathrm{Nm}$ at $998.5 \mathrm{rpm}$

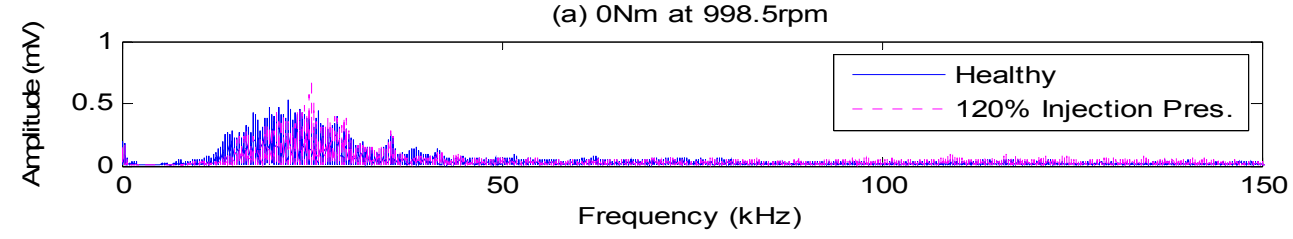

(b) $50 \mathrm{Nm}$ at $998.5 \mathrm{rpm}$

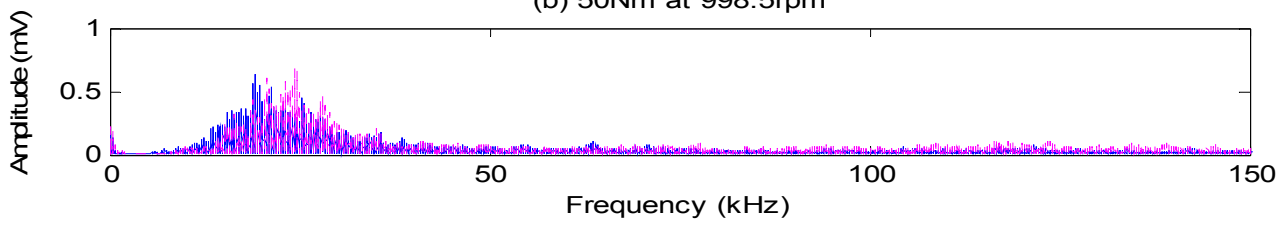

(c) $100 \mathrm{Nm}$ at $998.5 \mathrm{rpm}$

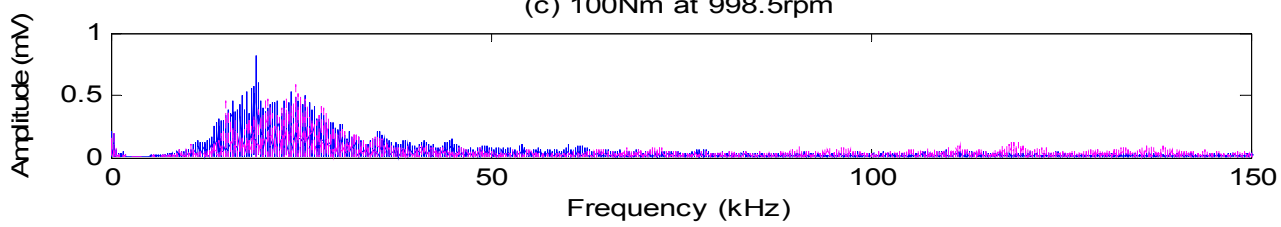

(d) $150 \mathrm{Nm}$ at $998.5 \mathrm{rpm}$

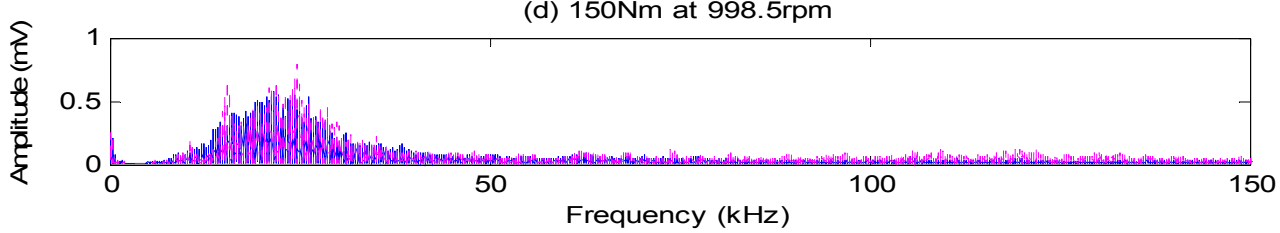

Figure 8. Spectra of the AE signals for $12 \%$ injection pressure
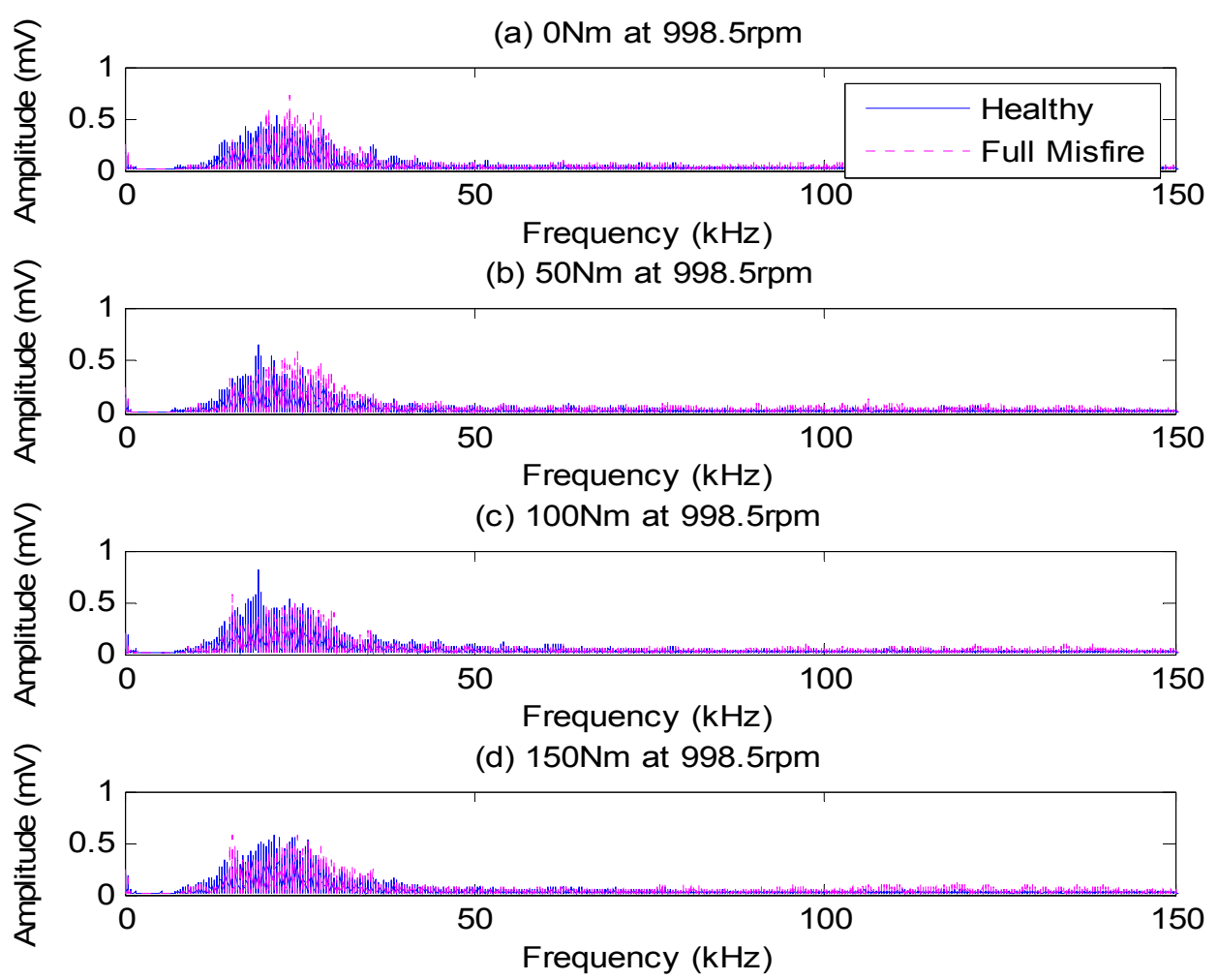

Figure 9. Spectra of the AE signals for full misfire 

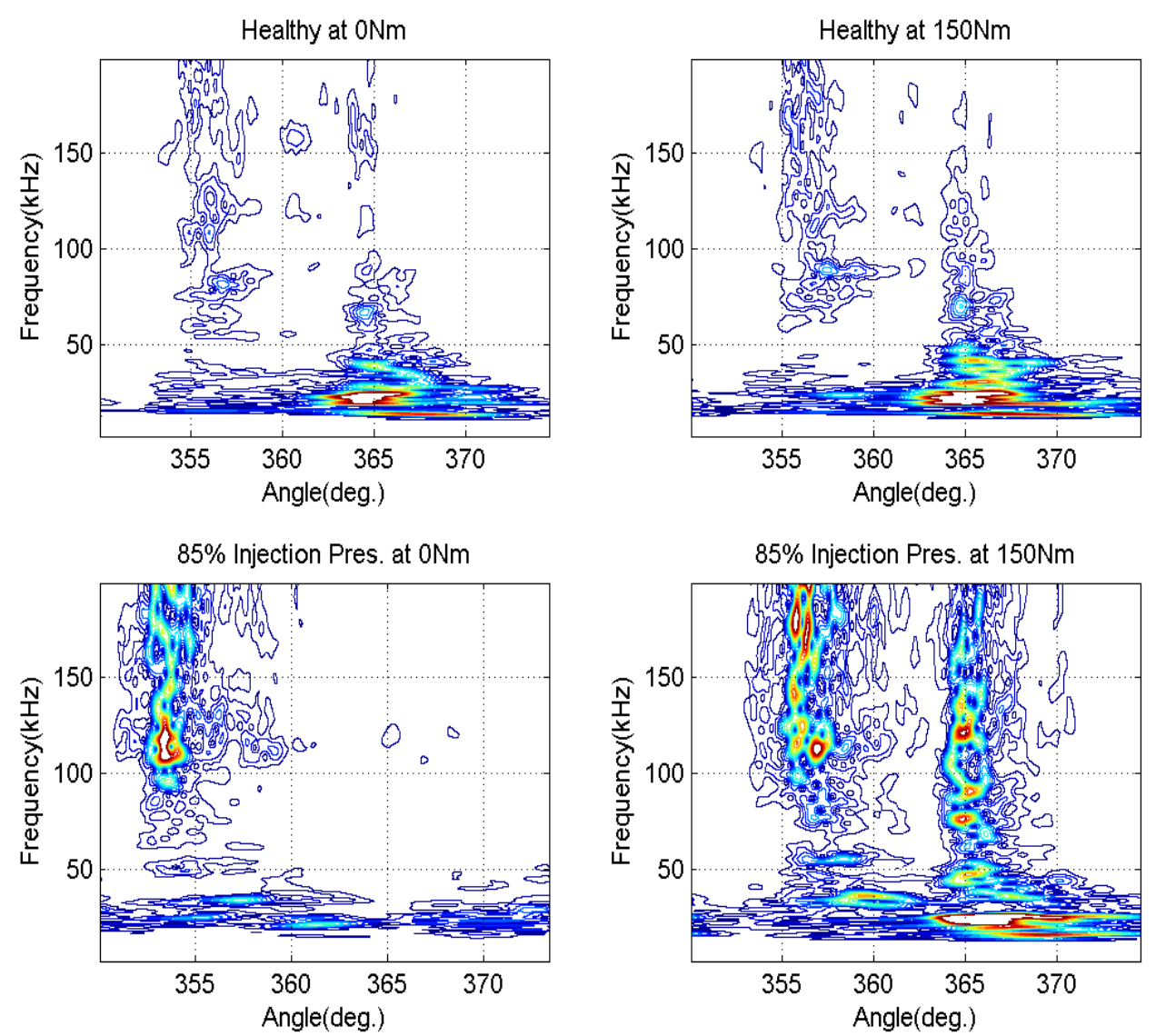

Figure 10. Angular-frequency representation of healthy and $85 \%$ injection pressure
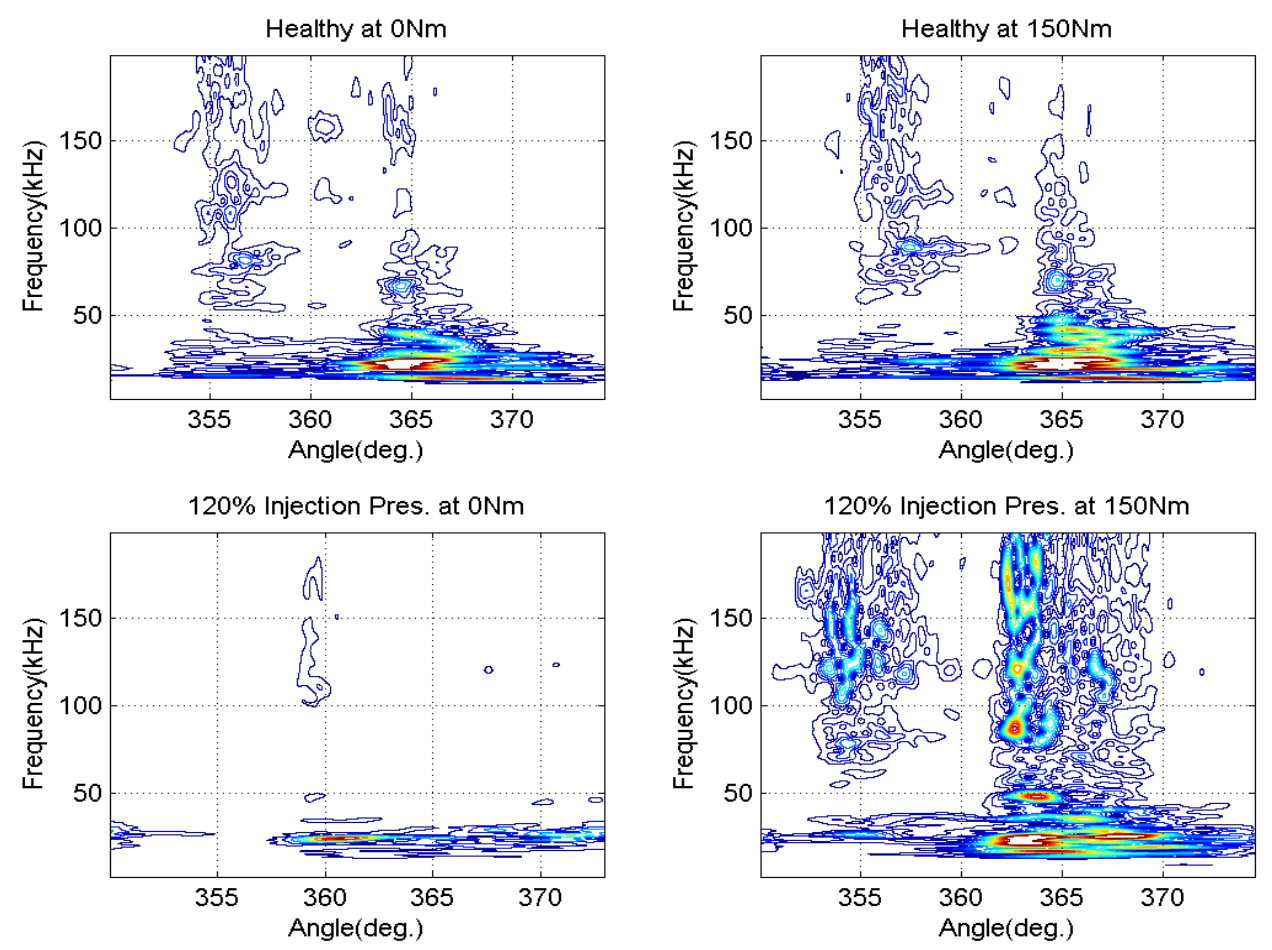

Figure 11. Angular-frequency representation of healthy and $120 \%$ injection pressure 

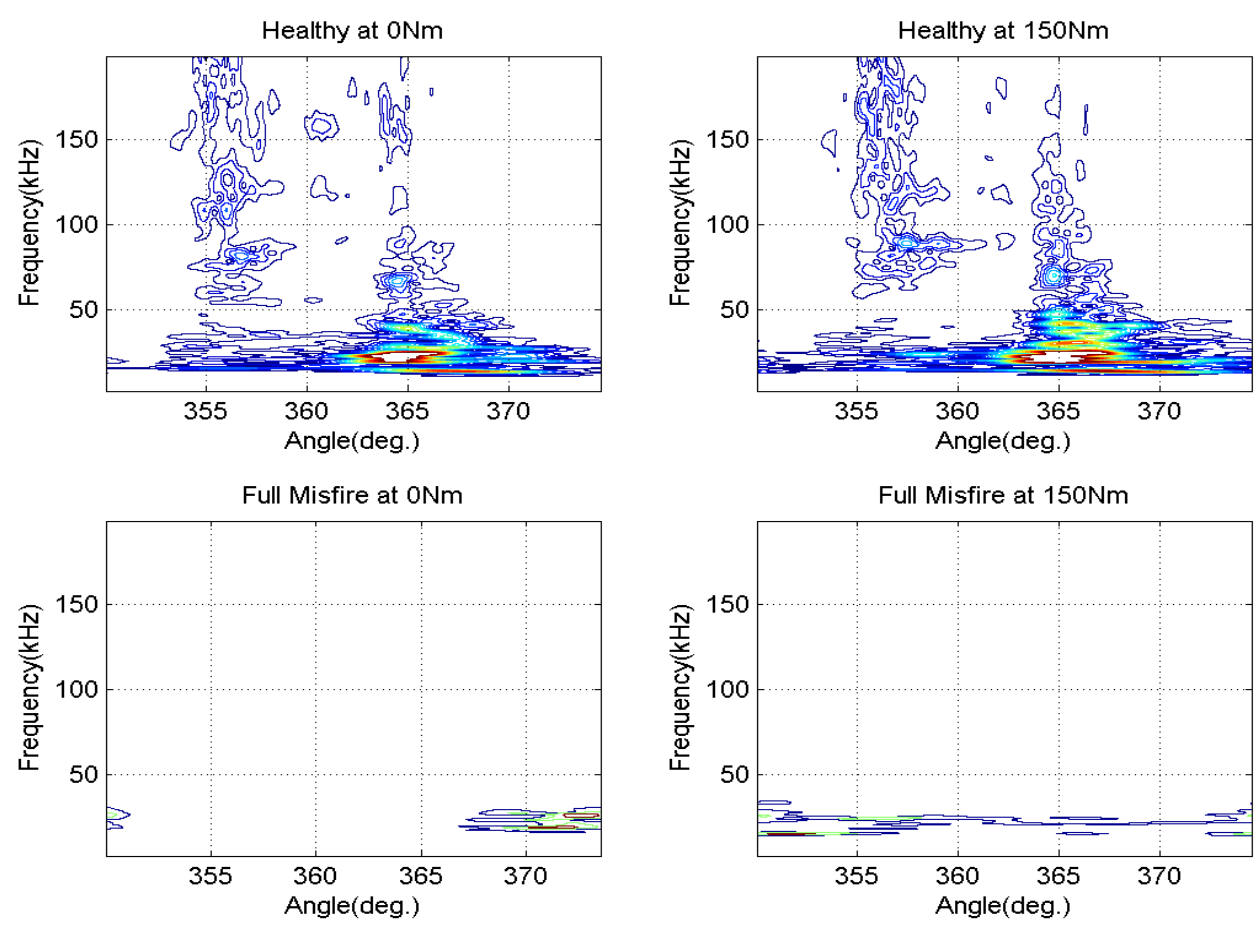

Figure 12. Angular-frequency representation of healthy and full misfire 